\title{
Jäähyväisluento
}

\section{Elämää ja estetiikkaa: Mitä taide on opettanut minulle johtajuudesta}

\author{
Professori Arja Ropon jäähyväisluento 13.11.2018,
}

Tampereen yliopisto

Rehtori, Dekaani, hyvä kollegat, opiskelijat ja ystävät

Olen Kouvolan tyttölyseon kasvatti. Kouvolan tyttölyseo oli Kouvolaan muuttanut Viipurin toinen tyttökoulu, jossa kulttuurin, historian ja taiteen korostus oli vahvasti esillä opetussuunnitelmassa. Opiskelimme jopa kokonaisen ylimääräisen vuoden taide- ja taitoaineiden ja kielten painotuksen takia.

Oma luokanvalvojani oli Viipurista muuttanut laulajatar, Lempi Olkku, kuuluisan virvokeja lakritsifirman sukua. Hän kertoi meille tarinoita siitä, miten hän esiintyi Viipurin Monrepos'n puistossa sunnuntai-iltapäivisin. Jotkut teistä ovat ehkä nähneet niitä kaarevia siltoja ja esiintymislavoja Monrepos'n puistossa tai ainakin kuvia niistä. Viime vuonna tuota nostalgista suomalaista historiaa tuhottiin puskutraktoreilla. Lempi Olkun tunneilla tuli varmasti tutuksi kaikki klassiset musiikkikappaleet.

Myös meitä oppilaita innostettiin omiin musiikkiopintoihin. Olihan paikkakunnalle juuri perustettu musiikkiopisto. Musiikkiopistoon minäkin päädyin: soittamaan viulua. Ja paras soitonopettajani siellä oli Tampereelta Kouvolaan muuttanut kapellimestari ja viulisti Eero Bister, kuuluisaa Bisterien musiikkisukua.

Ajattelin tuolloin, että minusta tulee orkesterimuusikko. Mietin jopa lukion keskeyttämistä ja Sibelius-Akatemiaan pyrkimistä. En kuitenkaan koskaan uskaltanut tehdä kumpaakaan. Rima oli liian korkealla kummankin osalta. Oli ehkä minun onneni, etten sille tielle lähtenyt. Viulisteja on kautta aikojen koulutettu liikaa työpaikkoihin nähden.

Ja voihan siihen olla muitakin syitä, etten päätynyt ammattimuusikoksi. Kerran, kun har- joittelin vinttihuoneessani, äitini ihmetteli, että kissako se siellä naukuu sisään päästäkseen ja meni eteiseen katsomaan. "Ai, se onkin Arja, joka soittaa viulua yläkerrassa". Tuttavapiirissä minua kutsuttiin leikillisesti Beethoveniksi.

Pienessä Kouvolan kaupungissa, kaupunginorkesterin soittajana ja hikipinkona koulussa koin olevani aina esillä: kaikki tunsivat tai ainakin tunnistivat minut. Bussimatkoilla kouluun minua kiusoiteltiin jatkuvasta viulukotelon kantamisesta. Jossain vaiheessa sanoinkin, että siellä on eväät pitkien päivien varalta. Muutin jopa lukioajaksi maalta kaupunkiin orkesteriharjoitusten takia.

Sibelius-Akatemian sijaan päädyin järkevistä syistä opiskelemaan kauppatieteitä vuonna 1973, vaikka eräs setäni arveli, että "eikös se ole sellainen miesten ala?" Silloin pääsi pelkillä papereilla sisään, ja minut hyväksyttiin Helsingin ja Turun kauppakorkeakouluihin sekä Tampereen yliopistoon. Kun valitsin Tampereen henkilökohtaisista syistä (syy oli tuleva mieheni Eero), eräs tuttu juristi kysyi, "Voiko Tampereelta tulla mitään hyvää?" Olen myös Tampereen yliopiston kasvatti. Olen aina ollut ylpeä ja olen edelleenkin ylpeä ja kiitollinen siitä, että olen saanut kasvaa kauppatieteilijänä osana monitieteistä yhteiskuntatutkimuksen yhteisöä Tampereen yliopistossa.

Ajattelin silloin opiskelujen alussa, että musiikki ja taide ovat nyt taakse jäänyttä elämää, jotain, mitä tein vain harrastuksena kouluaikana. Joitain vuosia tosin jatkoin soittotuntien ottamista myös Tampereella. Viimeinen opettajani oli unkarilainen, ankara viulutaiteilijatäti, joka totesi hehkuttaessani parhaan taitoni mukaan Beethovenin Romanssia, että "Da war schon etwas davon", eli että "olihan se vähän sinne päin". 
Nyt olin suuressa kaupungissa, opiskelin jotain todellista, oikeaa työelämää varten, jotain missä on järkeä. Musiikki ja taide saa jäädä.

Kuinka väärässä olinkaan! Onneksi.

Ajattelen nyt, että nimenomaan tämä kulttuuri- ja taidepainotteinen koulutaustani on oman eletyn elämäni (Lebenswelt, lifesworld) ja kokemusteni kautta luonut tilaa ymmärtää maailmaa ja johtamista/johtajuutta toisella tavalla - esteettisenä ja kehollisena ilmiönä.

\section{JOHTAJUUDEN ONTO-EPISTEMOLOGINEN LUONNE}

Valtavirtaiset johtajuusteoriat, joita koskevia tutkimuksia julkaistaan korkeimmin rankatuissa tiedelehdissä, fokusoituvat edelleen varsin johtajakeskeiseen ajatteluun, johtajan taitoihin, karismaan, osaamiseen: johtaja sitä, johtaja tätä. Toinen tunnuspiirre näille teorioille on luja luottamus siihen, että asiat tapahtuvat lineaarisesti ja perustuvat ihmisten rationaaliseen toimintaan: kun teen tämän, niin tapahtuu tuo. Tai kun selitän miksi, niin kyllä fiksut ihmiset ymmärtävät. Häiriötekijöitä tähän malliin tuottavat ihmiset ja heihin liittyvä epävarmuus ja epätietoisuus. Loogis-lineaarinen ajattelu johtajuudesta luo illuusion hallitsemisesta, kontrollista ja tuloksen mittaamisen objektiivisuudesta - ja mikä epätodennäköisempää, se perustuu siihen, että paras tieto ja osaaminen on hierarkian yläpäässä, johtajilla. Hämmästyttävää kyllä, tällaista sankarijohtajuutta on harjoitettu ja harjoitetaan edelleen näkyvästi myös maailman korkeimmilla johtajapalleilla, puhumattakaan pienemmistä työelämän sfääreistä.

Oma johtajuusajatteluni ei perustu sankarilliselle yksilöjohtajuudelle, vaan arkiselle tekemiselle, jossa toki voi ja pitääkin olla rakenteita, rooleja ja järjestystä.

Kun puhun johtajuudesta esteettisenä ja kehollisena ilmiönä, en viittaa kauneuteen enkä johtajien fyysiseen olemukseen, ulkonäköön tai vastaavaan. Tahallisesti tai tahattomasti kehollisen ja esteettisen näkökulman tuominen organisaatio- ja yrityselämän käytäntöjen ymmärtämiseen on tuottanut kohdalleni mediaseksikkäitä otsikoita kuten "Vedä koko vartalolla" (Talouselämä 2004: 9, 86) tai ihon alle meneviä arvioita, joissa kyseenalaistetaan moraalini ih- misenä ja naisena, kun puhun johtajuuden kehollisuudesta. Ilmeisesti keho on vain naisten ominaisuus.

Olen kiinnostunut johtajuudesta arkisina käytäntöinä ihmisten välillä, olivat he sitten muodollisesti johtajia tai alaisia. Johtajuus syntyy välitilassa, space-between, ei niinkään entiteettisesti johtajien ja alaisten piirteissä tai ominaisuuksissa. Johtajuuskäytäntöjä ovat erilaiset kohtaamiset työpaikalla, erilaisissa fyysisissä tiloissa. Niitä ovat kokoukset, puhumisen tavat, rutiinit, mutta myös sanattomat eleet, katseet, ilmeet, tunteiden esiin tuominen tai niiden piilottaminen. Näissä käytännöissä syntyy enemmän johtajuutta kuin yhdenkään johtajan tekemisissä - ja myös niistä huolimatta. Näissä käytännöissä luodaan tekemisen suuntaa, tavoitteita, tekemisen tapoja, neuvotellaan asioista. Nämä käytännöt innostavat, energisoivat, luovat yhteisöllisyyttä ja työn iloa tai sitten lannistavat, vähättelevät ja jättävät ulkopuolelle.

Tällaiseen johtajuuden ymmärtämiseen tarvitaan muutakin kuin loogis-rationaalista tietämisen tapaa. Tarvitaan toisenlaista käsitystä johtajuuden ilmiöstä. Johtajuuden ymmärtäminen esteettisenä kokemuksena perustuu ajatukseen, että tieto, tässä tapauksessa käsitys siitä, mistä johtajuudessa on kysymys, ei synny vain pään sisällä älynä ja loogisina rakenteina, vaan koko kehomme kautta tulevina aistikokemuksina, emootioina ja eletyn elämän muistijälkinä. Mieli ja keho ovat vahvasti yhteydessä toisiinsa, ei tosin siten, miten valtavirtaisen johtajuusteorian filosofiassa ajatellaan, että mieli ohjaa sille alisteista kehoa. Jo arkikokemus kertoo meille toisin. Jos yrität opettaa pienelle lapselle, että "ei saa koskea kuuman uunin luukkuun, siitä tulee pipi”, hän tuskin siitä paljon viisastuu, koska hän ei vielä tunnista abstrakteja käsitteitä, kuten "uunin luukku", "kuuma" ja "sattuu". Mutta usein jo yksikin fyysinen koskeminen kuumaan luukkuun synnyttää kehollisen tiedon ja muistin, josta muodostuu ymmärrys "uunin luukku tekee kipeää, siihen ei ole hyvä koskea".

Tämä yksinkertainen esimerkki osoittaa, kuinka elintärkeää kehon kautta tuleva tieto on, tässä tapauksessa lapselle, miksei siis myös meille aikuisille, kun yritämme ymmärtää erilaisia ilmiöitä ihmisten maailmassa, mitä myös johtajuus ja työelämä mitä ilmeisimmin ovat. 


\section{ESITTÄVÄT TAITEET JA JOHTAJUUS}

Itselleni erilaiset taiteen muodot, erityisesti esittävät taiteet, kuten orkesteri, teatteri ja osin myös tanssi ovat antaneet paljon virikkeitä ja käsitteitä johtajuuden uudenlaiseen hahmottamiseen.

Tunnettu johtamisajattelija Chester Barnard on jo vuonna 1938 tuonut esiin, että johtaminen on enemmän esteettiseen kuin loogiseen ajatteluun perustuvaa tietoa: "management is aesthetic rather than logical and better described by terms such as feeling, judgment, and sense" (Barnard 1938).

Hänen jälkeensä ovat monet muutkin tuoneet ajatuksen siitä, että johtajuus on enemmän taidetta kuin tiedettä (DePree 1989; Vaill 1989; Grint 2000; Ladkin \& Taylor 2010). Usein se on jäänyt pelkäksi toteamukseksi ilman perusteellisempaa pohdintaa, mutta viimeisten parinkymmenen vuoden aikana se on otettu vakavasti myös tutkimuksellisesti.

Haluan nostaa seuraavaksi muutaman asian, jotka ovat muotoilleet ymmärrystäni johtajuudesta eri taidemuotojen kautta esteettisenä ilmiönä ja kehollisina käytäntöinä. Nämä perustuvat sekä omiin että muiden tutkimuksiin. On mielenkiintoista havaita, että useilla tutkijoilla, jotka ovat kirjoittaneet johtajuudesta estetiikan ja kehollisuuden näkökulmasta, on henkilökohtainen kokemus jostain taiteen muodosta, on se sitten kuoron tai orkesterin johtoa (kuten edesmennellä Grete Wennesillä), tanssia (kuten Jaana Parviaisella), kuvataidetta (kuten Nancy Adlerilla ja Steve Taylorilla), kitaransoittoa ja säveltämistä (kuten Perttu Salovaaralla) tai sinfoniaorkesterissa soittamista kuten minulla.

Tässä kohtaa on korostettava, että ei ole kyse esteettisyydestä johtajuustyylinä. Pikemminkin yritän sanoa, että ymmärtääkseen mistä johtajuudessa on kysymys esteettisestä ja kehollisesta näkökulmasta, on tärkeä kiinnittää huomio tiettyihin asioihin johtajuuden rakentumisessa. Jokainen ratkaisee kohdallaan, kuinka tämä toteutuu käytännössä.

Ensinnäkin intensiivinen läsnäolo on sellainen, joka tulee vahvasti esiin taiteellisessa esittävässä työssä, kuten orkesterissa tai teatterissa.

Jotta taiteellinen performatiivinen produktio voi syntyä, ihmisten täytyy olla vahvasti fyysisesti ja henkisesti läsnä siinä, mitä ollaan tekemässä. Tämä ei tarkoita sitä, että työtä tai sen valmistelua ei voisi tehdä myös muualla. Esimerkiksi monia luovan työn vaiheita on tarpeen ja välttämätöntäkin tehdä yksin ja omassa hiljaisessa tilassa. Mutta silloin kun ollaan yhdessä, ollaan todella 110-prosenttisesti läsnä ilman mitään ulkopuolista häirintää, ei puhelimia, ei jatkuvaa viestintää netissä. Teatterin tekijät tunnistavat käsitteen "pyhä paikka" (sacred place), josta on tehty viime aikoina myös organisaatio- ja johtamistutkimusta. Teatterityössä pyhä paikka on näyttämö, jolla oltaessa kaikki ulkopuolinen yhteydenpito on totaalisen kielletty. Tässä voisi olla oppimisen paikka myös meille muille. Näyttäähän esimerkiksi kännykästä tulleen lähes jokaisella käden jatke tai kolmas korva.

Toinen todella tärkeä asia, jonka olen oppinut taideorganisaatiosta, erityisesti orkesterissa työskentelystä on kuuntelu. Voisi ajatella, että orkesterissa keskeistä on soittaminen ja kapellimestarin tulkinnan välittäminen teoksesta. On tunnettu kasku, että jos uusi kapellimestari äityy kovasti puhumaan ja selittämään mitä haluaa, muusikot kysyvät: "tultiinko tänne puhumaan vai soittamaan". Kapellimestarin roolia ja tehtävää on hyvin kuvattu sanomalla, että kapellimestari on säveltäjän puolustusasianajaja, ei tulkki.

Taiteellisen tuottamisen prosessi on paljon puhetta monimuotoisempaa. Toisin kuin yleensä ajatellaan hyvästä johtajuudesta ja sen tuloksellisuudesta, puhuminen ja karismaattinen esiintyminen orkesterin edessä ei olekaan keskeisintä orkesterin johtamisessa. Tuloksen laadun suhteen tärkeintä on kuuntelu: oman soiton kuuntelu, vieruskaverin soiton kuuntelu, vieressä olevan soitinryhmän soinnin kuuntelu, kauempana olevan soitinryhmän kuuntelu. Ja koko ajan oman soittamisen suhteuttaminen muiden ääniin. Kapellimestarin tehtävänä on kuunnella koko porukan soundia ja ohjata sitä pienillä eleillä, katseilla, käden liikkeillä. Ja mikä tärkeintä, kuka tahansa voi varsin pienillä liikkeillä, tahattomasti tai tahallisesti, vaikuttaa lopputuloksen suuntaan.

Kuuntelu ei viittaa esteettisessä mielessä kuuloaistiin, vaan kuuntelulla on tekemisen substanssiin, esimerkiksi johtamiseen liittyvä ulottuvuus. Donna Ladkinin (2008) mukaan kuuntelu ja esteettinen harkinta liittyvät kiinteästi toisiinsa. Esteettinen harkinta tai tilanteen 
arviointi perustuu oman alan ammatilliseen, kokonaisvaltaiseen hallintaan (master of the field), mikä edellyttää huomion kohdistamista tässä ja nyt, näkemyksellisyyttä ja asioiden suhteuttamista toisiinsa. Kuuntelu ei ole vain sattumanvaraisia tai hetkellisiä kuulohavaintoja. Kun kuuntelee toista, reflektoi myös itseään, identiteettiään ja suhteuttaa kuulemansa oman elämänsä tarinaan.

Taiteellisen produktion, esimerkiksi orkesterin menestyminen on mitä suuremmassa määrin kollektiivisen prosessin tuotos, jossa yksittäisen johtajan, kapellimestarin, rooli ja osaaminen on toki tärkeä, mutta lopputulos on vahvasti kaikkien soittajien yhteinen panos. Hieman harhaanjohtavasti kapellimestari näyttäytyy yleisölle yksilöllisenä sankarijohtajana, ja tätä näkyä käytetään paljon metaforisesti ja visuaalisesti tavoiteltavana johtajuutena myös yrityselämässä. Toki kapellimestarilla on tunnustettu ammatillisesti hierarkkinen positio orkesterissa. Kuitenkin itse musiikin tuottamisen prosessi on vahvasti vuorovaikutuksellista, jossa johtajuus syntyy vuoropuheluna eikä kapellimestarin autoritaarisena vallankäyttönä. Ann-Sofie Köping (2007) käyttää termiä "kiertävä vaste" (circular response) kuvatessaan orkesterin esteettistä, vuorovaikutuksellista, jatkuvassa liikkeessä olevaa prosessimaista johtajuutta. Tunnettu kapellimestarien kouluttaja, Jorma Panula, on osuvasti kuvannut muusikoiden, oman alansa asiantuntijoiden, johtamista: "Auta, älä häiritse".

Kun seuraavan kerran olette sinfoniaorkesterin konsertissa, niin kiinnittäkääpä huomio siihen hetkeen, kun esitys päättyy: Kapellimestari kiittää ensin orkesteria ennen kuin kumartaa yleisölle. Tämä on kunnianosoitus yhdessä tekemiselle ja kollektiiviselle onnistumiselle.

Johtajuuden vuorovaikutuksellinen luonne orkesterissa ja myös teatterissa perustuu yhteyteen ja yhteyden luomiseen lähellä oleviin kollegoihin ja myös yleisöön. Niina Koivunen ja Grete Wennes (2011) korostavat sitä orkesteritutkimuksessaan. He puhuvat ympäristön sensitiivisestä tunnistamisesta, lähellä olevien huomioimisesta. He käyttävät jopa termiä "antautuminen" (surrender) kollegamuusikoiden soittamiselle.

Yhteyttä luodaan orkesterissa myös sillä, että soittajat ovat fyysisesti hyvin lähellä toisiaan. Olette ehkä huomanneet, että esimerkiksi kama- riorkesterissa soittajien kehot liikkuvat intuitiivisesti samaan suuntaan. Jaana Parviainen käyttää termiä kinesteettinen empatia. Orkesterissa soittaessa voi kuulla vieruskaverin hengityksen poskellaan tai niskassaan, haistaa kehojen hajuja. Sanan mukaisesti ollaan "sylkyetäisyydellä". Tällainen työ vaatii varsin suurta toleranssia sietää omaa ja muiden kehollisuutta. Toisaalta juuri kehollisuuden vahva rooli orkesterityössä auttaa ymmärtämään sitä, miten lopputulos kehkeytyy kapellimestarin ja soittajien yhteisen fyysisen ja mentaalisen ponnistelun kautta. Johtajuus rakentuu monen tekijän yhteen kietoutumisella (entanglement).

Teatterimaailma tuntee käsitteen "rakastava katse" (loving gaze). Ilman sitä ei synny hyvää produktion tekemisen prosessia eikä lopputulosta. Olen tutkinut Erika Sauerin kanssa katsekäytäntöjä teatteriproduktion harjoituksissa (Ropo \& Sauer 2006; Sauer \& Ropo 2007). Vaikka tässä tutkimuksessa huomio kohdistuikin ohjaajan katseisiin, on katse aina kuitenkin suhteessa tapahtuva ja usein hyvin tunnepitoisesti koettu.

Teatterin harjoituksissa luotiin monenlaisia kulttuurisia katseita, niitä koettiin eri tavoin, ja niistä seurasi erilaisia lopputulemia.

Hirviömäinen katse koettiin teräväksi, uhkaavaksi, vaativaksi.

Teekutsujen katsekäytäntö oli kohteliasta, etäistä.

Perheidylliä kuvattiin lämpimäksi, rohkaisevaksi.

Elitistinen katse oli ironinen, ylimielinen.

Katseiden kokemisen ja näytelmän taiteellisen ja taloudellisen menestymisen yhteys oli varsin yllättävä: Hirviömäisiksi kuvatut vaativat katseet saivat näyttelijät ylittämään itsensä, ja produktiosta tuli menestys. Positiivinen perheidylli koettiin valtaistumisena ja yhteisenä onnistumisena. Sen sijaan teekutsumainen kohtelias katseiden vaihtaminen tuotti rutiinimaista, business as usual -teatteria. Ylimielisessä katsomisen kulttuurissa näyttelijät kokivat tulleensa petetyiksi ja hylätyiksi, mikä näkyi myös lopputuloksessa.

Johtajuuden estetiikka ei todellakaan ole vain kaikkea kaunista ja hyvää. Aistikokemukset, emootiot ja kehon muisti, historia tuovat siihen inhimillistä särmää, ahdistusta ja myös konflikteja. 
Taiteellinen produktio on ainutlaatuinen, sitä ei voi täysin samanlaisena toistaa. Sen tekeminen tapahtuu kehollisissa arkikäytännöissä muiden ihmisten kanssa ja tietyssä fyysisessä ja kulttuurisessa ympäristössä. Johtajuus rakentuu näissä arkisissa kohtaamisissa ohikiitävinä, hetkellisinä, ja särkyvinäkin kehollisina kokemuksina, jotka jäävät muistiin ja vaikuttavat ajassa. Juuri tästä syystä on tärkeä arvostaa arkea ja jokapäiväisiä kohtaamisia, suunniteltuja tai suunnittelemattomia. Niissä tapahtuu johtajuutta.

\section{ESTEETTISEN JA KEHOLLISEN JOHTAJUUSAJATTELUN INSTITUTIONALISOITUMINEN}

Ymmärrykseni johtajuudesta ei ole vain yksilöllistä ajatteluani, vaan se liittyy suurempaan kehityslinjaan. Esteettinen näkökulma johtajuuteen ja organisaatioiden toimintaan on pikkuhiljaa saanut jalansijaa myös johtamisen alan konferensseissa, julkaisuissa ja koulutuksessa. Voidaan jopa sanoa, että organisaatioestetiikka on siltä osin institutionalisoitunut. 1980-luvun puolivälissä alkanut keskustelu lähinnä italialaisten tutkijoiden Antonio Strati, Mauro Guillén ja Pascale Gagliardi johdolla, sai alkunsa vastalauseena positivistiselle loogis-lineaariselle paradigmalle ja sen puutteille ymmärtää organisatorisia ilmiöitä. Syntyi SCOS-konferenssi (Standing Conference on Organizational Symbolism) korostamaan organisaatioiden symbolisia todellisuuksia. Perustettiin lehti Aesthesis, myöhemmin Organizational Aesthetics, jonka kantava voima ja editori on Steven Taylor, elokuussa 2018 Tampereellakin vieraillut amerikkalaistutkija.

Esteettinen johtajuustutkimus on vuoden 2014 review-artikkelissa (Dinh, Lord, Gardner, Meuser, Liden \& Hu 2014) luettu etabloituneiden tutkimustraditioiden joukkoon. Mukavaa oli, että siinä meidän (Hansen, Ropo \& Sauer 2007) artikkeli Leadership Quarterly -lehdessä oli otettu esimerkiksi.

Jopa Academy of Management -konferenssissa, joka on johtamisen alan mammuttikonferenssi, annettiin noin kymmenen vuoden ajan tilaa ns. Fringe cafe -konseptille, jossa oli mahdollista tuoda esiin toisenlaisia, taidepohjaisia, tutkimuksen tekemis- ja esitystapoja. Muun muassa vuonna 2008 Anaheimin konferenssissa oli Tango Symposiumi, johon minut kutsuttiin kommentoimaan ja keskustelemaan johtajuudesta ja tanssista.

Art of Management -konferenssi (AoMo) taas on jo lähes kymmenen vuoden ajan kerännyt sekä käytännön taiteilijoita että alan tutkijoita yhteisiin keskusteluihin.

Muita konferensseja, joissa taiteen ja kulttuurin johtaminen on vahvasti esillä, on yli 10 vuotta toiminut AIMAC (International Conference on Arts and Cultural Management).

International Leadership Association'n (ILA) suurimmassa alan konferenssissa on muotoutunut jopa oma yhteisönsä, "Arts \& Leadership Learning Community". Myös European Group of Organization Studies -konferenssissa (EGOS) on lisääntynyt tämän tyyppisen tutkimuksen esittely.

Taidemuotojen antia organisaatiointerventioille on esitelty useissa julkaisuissa (esim. Darsœ 2004; Berthoin Antal ym. 2018). Varsinaisesti johtajuuden estetiikkaa ja kehollisuutta koskeva tutkimus alkoi kuitenkin vasta 2000luvun alussa (Ropo \& Parviainen 2001; Ropo ym. 2002; Koivunen 2002; Sauer 2005). Niissä käytettiin eri taiteen aloja illustroimaan näkökulmaa.

Useat kauppakorkeakoulut ja liikkeenjohdon koulutuskeskukset ovat perustaneet kokonaisia ohjelmia taide, talous ja johtaminen -teemojen ympärille (esim. Copenhagen Business School Tanskassa, Bled School of Management Sloveniassa ja Banff Centre Kanadassa).

\section{LOPUKSI}

Uusi Tampereen yliopisto aloittaa vuoden 2019 alussa entistä monitieteisempänä. Hieman minua on jäänyt askarruttamaan yliopiston uusi logo, jossa on korostetusti kuvattu vain pää, ei koko ihmistä, puhumattakaan siitä, että olisi useampia ihmisiä. Väkisinkin tulee tuota logoa katsellessa mieleen epäilys, että annettaisiin ymmärtää ihmisten, organisaatioiden, yhteiskuntien ja kulttuurien olevan redusoitavissa yksilön aivoihin ja älyyn. Toivottavasti tätä ei ole tarkoitettu. Ja toivottavasti taiteet ja kulttuuri voisivat olla jatkossakin avaamassa uudenlaisia näkökulmia ihmiselämän ymmärtämiseen.

Tunnetun tamperelaisen liikenaisen ja kulttuurimesenaatin Sara Hildénin hautakiveen on kaiverrettu ranskalaisen impressionistin 
Auguste Renoir'n sanat: "Kun taide tulee tarpeettomaksi, loppu on alkanut". Tätä kannattaa ajatella myös uuden Tampereen yliopiston profiloitumisessa.

\section{LÄHTEET}

Barnard, Chester I. (1938). The functions of the executive. Cambridge, MA: Harvard University Press.

Berthoin Antal, A., Dubucquet, Gervaise \& Fremeaux, Sandrine (2018). Meaningful work and artistic interventions in organizations: Conceptual development and empirical exploration. Journal of Business Research, 85, 375385.

Darsœ, Lotta (2004). Artful creation: Learningtales of arts in business. Fredriksberg: Samfundslitteratur.

DePree, Max (1989). Leadership is an art. New York, NY: Dell.

Dinh, Jessica E., Lord, Robert G., Gardner, William L., Meuser, Jeremy D., Liden, Robert C. \& Hu, Jinuy (2014). Leadership theory and research in the new millennium: Current theoretical trends and changing perspectives. The Leadership Quarterly, 25, 36-62.

Grint, Keith (2000). The arts of leadership. Oxford: Oxford University Press.

Koivunen, Niina (2003). Leadership in symphony orchestras. Discursive and aesthetic practices. Tampere: Tampere University Press.

Koivunen, Niina \& Wennes, Grete (2011). Show us the sound: aesthetic leadership of symphony orchestra conductors. Leadership, 7(1), 51-71.

Köping, Ann-Sofie (2007). The creative compost: Playing and conducting musical events. Teoksessa Guillet de Monthoux, Pierre, Gustafsson, Claes \& Sjöstrand, Sven E. (Eds), Aesthetic leadership: Managing fields of flow in art and business (s. 15-32). Basingstoke, UK: Palgrave Macmillan.

Ladkin, Donna (2008). Leading beautifully: how mastery, congruence and purpose create the aesthetic of embodied leadership practice. The Leadership Quarterly, 19, 31-41.
Toivotan onnea ja menestystä uudelle Tampereen yliopistolle, teille rakkaat kollegat ja opiskelijat tässä yhteisössä.

Kiitos, että olen saanut olla osa tätä yhteisöä 45 vuoden ajan.

Ladkin, Donna (2010). Rethinking leadership. A new look at old leadership questions. Cheltenham, UK: Edward Elgar.

Ladkin, Donna \& Taylor, Steven S. (2010). Leadership as art: variations on a theme. Leadership, 6(3), 235-241.

Hansen, Hans, Ropo, Arja \& Sauer, Erika (2007) Aesthetic leadership. The Leadership Quarterly, 18 (6), 544-560.

Ropo, Arja \& Parviainen, Jaana (2001) Leadership and bodily knowledge in expert organizations. Scandinavian Journal of Management, 17 (1), 1-18.

Ropo, Arja, Parviainen, Jaana \& Koivunen, Niina (2002) Aesthetics in leadership. Teoksessa Parry, Ken W. \& Meindl, Jim R. (Eds), Grounding Leadership Theory and Research (s. 21-38). Greenwich, Connecticut: Information Age Publishing.

Ropo, Arja \& Sauer, Erika (2006) Leadership and the driving force of shame: A social constructionist analysis of narrative. Teoksessa Zerbe, Wilfred J., Ashkanasy, Neal M. \& Härtel, Charmine E.J. (Eds), Individual and Organizational Perspectives on Emotion Management and Display (s. 57-80) Oxford: Elsevier.

Sauer, Erika (2005). Emotions in leadership. Leading a dramatic ensemble. Tampere, Finland: Tampere University Press.

Sauer, Erika \& Ropo, Arja (2007) Leading by gaze. Proceedings of the International Conference on Arts and Cultural Management, 8-11 July, Valencia.

Vaill, Peter B.(1989). Managing as a performing art. New ideas for a world of chaotic change. San Francisco: Jossey-Bass. 